\title{
Influence of Achievement Motivation on Nigerian Undergraduates' Attitude towards Examination
}

\section{Lateef Omotosho Adegboyega}

Department of Counsellor Education, Faculty of Education, University of Ilorin, Ilorin, Nigeria, adegboyega.lo@unilorin.edu.ng

This paper investigated the influence of achievement motivation on Nigerian undergraduates' attitude towards examination. Descriptive survey of the correlational type was employed for the study. One thousand, five hundred and thirty-six $(1,536)$ undergraduates in Nigeria were drawn using purposive and stratified sampling techniques. Four research questions were generated to guide the application of the study, while two null hypotheses were formulated and tested at 0.05 alpha level. Achievement Motivation Scale" (AMS) and "Attitude Towards Examination Scale" (ATES) were the instruments used to collect relevant data. The findings revealed that majority of Nigerian undergraduates have a high level of achievement motivation. The findings also revealed that majority of Nigerian undergraduates have a positive attitude towards examination. There was a significant correlation between achievement motivation and attitude of Nigerian undergraduates towards examination. The findings also revealed that gender, age, level of study, university and family type had a significant positive influence on undergraduates' achievement motivation and attitude towards examination in Nigeria. It was therefore recommended, among others that counsellors and lecturers should be properly equipped with strategies needed to assist students in developing appropriate achievement motivation level so as to promote positive attitude towards examination.

Keywords: achievement motivation, attitude towards examination, undergraduates, motivation, examination, Nigeria

\section{INTRODUCTION}

Achievement motivation is one's determination to succeed in academic studies. It includes academic aspiration and attitude towards school. Achievement motivation refers to a pattern of actions and feelings connected to striving to achieve some internalized standard of excellence in performance (Gesinde, 2000). Achievement oriented behaviour is a function of a number of factors including the motive to succeed, the motive to avoid failure, the perceived probability of success and the incentive value

Citation: Adegboyega, L. O. (2018). Influence of Achievement Motivation on Nigerian Undergraduates' Attitude towards Examination. International Journal of Instruction, 11(1), 77-88. https://doi.org/10.12973/iji.2018.1116a 
of success (Paul, 1982). All these are influenced by an individual's emotional state of mind. Students low on emotional intelligence may find failure more difficult to deal with, which undermines their academic motivation (Drago, 2004).

Motivation in education affects the level of the learning of individuals and as well as reflects on their behaviours what they have learned or not. The motivation of students represents the active participation of the students in learning process. The curiosity and interest of the students manifest itself with the connection to the subject learned, focus on the process of learning lesson and the joy of learning (Cladella, \& Herlin, 2002).

The definitions of motive and motivation were made by many researchers. The common side of these definitions is motivation being "the driving force activating behaviour" (Dörnyei, 2001). Some of the definitions of motive and motivation are as follows: motive is the power that gives strength and direction to the behaviour; this power causes to act for a purpose by affecting organism (Dörnyei, 2001). Motive is the driving force activating the organism, giving energy, causing a sensory uplift (enthusiasm, desire) and directing behaviour to achieve some specific purposes in certain situations (Fidan, 1993). Motivation is a desire to succeed in a goal which is meaningful to the individual (Cladella \& Herlin, 2002). Students' learning is maximized when their achievement motivation is enhanced. Motivation has also been defined by hedonists in terms of imaginative responses. The authors use the word motive to design learned anticipations (expectations of rewards) or punishment. An individual has fear motive or an anxiety motive if and when he is exposed to cues that have previously been followed by punishment.

Motivation tries to explain the reason why people decide to do something, with which decision they go after, their willingness, and how long they are willing (Dörnyei, 2001). A large number of theories have been proposed to explain the process of incentive motivation. These theories have emphasized different aspects of the concept of motivation. Motivation is one of the theories of "achievement motivation" proposed by Atkinson expectancy-value theory. In essence, this theory of motivation focuses on the process of explaining the need for achievement and fear of failure (Brophy, 1998). Achievement motivation can be defined as making good business or the orientation to the actions which are important to compel with the perfect standards (Nouhi, Shakoori, \& Nakhei, 2008).

The achievements of the students in courses are usually determined by the scores in examinations. Achievement motivation ensures that a student uses all his time and energy to achieve the standard objectives set before him (Nuthana \& Yenagi, 2009).

Goc (2010) outlined the factors affecting students' achievement motivation as: effectiveness of the teacher, friends, the individual's attitude towards school, students' perceptions about their own abilities, past experiences (positive or negative), the importance given to the student's success, parent's approaches towards their children and school by taking into account the researches done.

Achievement motivation can also be seen as self determination to succeed in whatever activities one engages in. It can be academic work, professional work, sporting events, 
and many others. Gesinde (2000) posited that the urge to achieve varies from one individual to another. While some individuals' need for achievement is very high, others may be very low. However, in life, there are high achievers and low achievers. What is responsible for the variation could be the fact that achievement motivation is believed to be learnt during socialization processes and learning experiences. As a matter of fact, this varies from one individual to another. Gesinde (2000) asserted further that those who have high achievers as their models in their early life would develop the high need to achieve. On the other hand, those who have low achievers as their models would hardly develop the need to achieve in life. Humans are said to be either extrinsically or intrinsically motivated. Intrinsic motivation is said to be derived internally on the job itself. It is that which occurs while a person is performing an activity in which they take delight and satisfaction. Intrinsic motivation is seen as internal reward, while extrinsic motivation is a reward that a person can enjoy after finishing the task.

Okoye (1985) observed that motivation holds the key to the understanding of human behaviour. This explains why one individual dodges work, but another works normally in satisfaction to its greater heights of performance. Other individuals resort to illegal and unconventional methods of achieving social, academic, economic and political recognition. Motivation should also be carefully handled, whether in the work, or study situations; such that students are neither under-motivated nor over-motivated but appropriately motivated to achieve in the society.

Motivation is one of the factors that affect students' performance in school. It is also referred to as academic engagement, which has to do with the cognitive, emotional, and behavioural indicators of student investment in their attachment to education (Tucker, Zayco \& Herman, 2002). It is obvious that students who are not motivated to succeed will not work hard. In fact, several researchers have suggested that only motivation directly affects academic achievement. Other factors affect it only through their effect on motivation (Tucker, Zayco \& Herman, 2002). However, these authors expressed that it is not easy to understand what motivates students.

Numerous studies have been conducted on this topic, which have led to the development of several theories of motivation. Goal motivation theory, for example, which is one of the widely accepted theories of motivation, postulates that there are two main types of motivation for achievement at school. Students with an ability or performance goal orientation are concerned with proving their competence by getting good grades or performing well compared to other students (Nuthanap, 2007).

On the other hand, students with a task goal orientation are motivated by a desire to increase their knowledge on a subject or by the enjoyment from learning the material. Studies have shown that students with a task goal orientation are more likely to engage in challenging tasks, seek help as needed, and adopt useful cognitive strategies, and, possibly most importantly, tend to be happier both with school and with selves as learners. Subsequent research has suggested, however, that despite its potential implications for middle school policy and curriculum design, a different perspective of either "task-based" or "performance-based" goal may be too simplistic of a model of adolescent motivation (Dowson \& McInerney, 2001). 
Research has also suggested that task and performance goals are not mutually exclusive. While many experimental studies forced research participants to select one goal orientation or the other, correlation research has found that individuals' endorsement of a task goal orientation is often weakly correlated or uncorrelated with endorsement of an achievement motivation goal orientation (Kaplan \& Maehr, 2007).

The focus of this study was on 100 to 400 level undergraduates' in Nigeria. It is worthy to note that, one must be able to understand what motivates students, what impacts their attitudes, what brings them to a University, and ultimately what will impact them to remain there until they finish. The researcher was interested in investigating the degree and nature of relationships among the variables involved in the study. This enables the researcher to ascertain the extent to which variation in one variable is related to variations in another variable. Thus, the researcher investigated the influence of achievement motivation on Nigerian undergraduates' attitude towards examination.

\section{Research Questions}

The following research questions were posed for the study:

1. What is the achievement motivation level of undergraduates in Nigeria?

2. What is the typical attitude of undergraduates in Nigeria towards examination?

3. Is there any correlation between achievement motivation and attitude of undergraduates towards examination?

4. To what extent will gender, age, level of study, university and family type influence undergraduates' achievement motivation and attitude towards examination?

\section{Research Hypotheses}

The following null hypotheses were generated to guide the conduct of this research thus:

1. There is no significant correlation between achievement motivation and attitude of undergraduates towards examination.

2. Gender, age, level of study, university and family type will not influence undergraduates' achievement motivation and attitude towards examination.

\section{METHOD}

\section{Research Design}

The research design adopted for this study was descriptive survey of the correlational type. According to Stangor (2004), correlational design is appropriate for measuring such complexities of the pattern of relationships that exists among measured variables. Correlational research design was preferred in this study because the design is capable of looking at the relationship between or among two or more variables. This is because the researcher was interested in finding out the influence of achievement motivation on undergraduates' attitude towards examination in Nigeria.

\section{Participants}

In a research process, sampling procedure is very crucial and must be appropriately considered. For this study, the population comprised all undergraduates in Nigeria, which was estimated at 1,855,000: Federal Universities $=1,150,000$; State Universities 
$=400,000$; and Private Universities $=305,000$ (Annual Reports of Universities in Nigeria, 2016). The target population, on the other hand, consisted of all undergraduates in Federal Universities in six selected states across the six geopolitical zones of Nigeria. Based on the Research Advisors (2006), a total sample size of 1,536 was recommended at $95 \%$ confidence and $2.5 \%$ margin of error. Based on this recommended figure i.e. 1,536 and for equal representation, 256 respondents were purposively selected from each of the six federal universities.

Purposive and stratified random sampling techniques were employed to select the respondents for the study. The technique comprised several stages of selection from the larger sampling framework to the actual sample size for the study. In giving the study a national spread, the existing six geopolitical zones of the federation were used as the sampling field.

At stage one; the researcher adopted the purposive sampling technique to ensure a national spread by deliberately selecting a state from each of the six geo-political zones in Nigeria. These states are: Enugu (South-East); Lagos (South-West); Edo (SouthSouth); Bauchi (North-East); Kaduna (North-West) and Kwara (North-Central). Furthermore, one Federal University was purposively selected from each of the six selected States. Thus, a total of six Federal Universities were purposively selected. At stage two, stratified random sampling technique was employed to select participants for the study.

\section{Data Collection Tools}

Two Questionnaires were used to collect the necessary data. In order to collect the data on achievement motivation; Achievement Motivation Scale (AMS) was adopted from Elliot and Mcgregor (2001) to measure achievement motivation. To measure attitude towards examination, the instrument in this section was developed by experts in the Department of Counsellor Education, University of Ilorin (2013) but was adapted to suit the objective of this study.

The highest score any respondent could obtain in AMS which contained items on achievement motivation was 80 (i.e. $4 \times 20)$ while the lowest score was $20(1 \times 20)$. Therefore, the range was $60(80-20)$. The range was divided by 2 (i.e. $60 / 2) 30$. Then, 30 was added to the lowest score on the AMS (i.e. $30+20=50$ ). Therefore, 50 was the benchmark for AMS. Hence, score between 20 and 50 was considered as low achievement motivation while score between 51 and 80 was considered high achievement motivation in this study.

The highest score any respondent could obtain in ATES which contained items on attitude towards examination was 80 (i.e. $4 \times 20)$ while the lowest score was $20(1 \times 20)$. Therefore, the range was $60(80-20)$. The range was divided by 2 (i.e. 60/2) 30. Then, 30 was added to the lowest score on the ATES (i.e. $30+20=50$ ). Therefore, 50 was the benchmark for ATES. Hence, score between 20 and 50 was considered as negative attitude towards examination while score between 51 and 80 was considered positive attitude towards examination in this study. 


\section{Data Analysis}

The data collected were analysed by the researcher using both descriptive and inferential statistical procedures. Percentage was used to answer research questions 1 and 2, while Person Product Moment Correlation (PPMC) statistical technique was used to analyse hypothesis 1 and Multiple Regression was used to analyse hypothesis 2 at 0.05 alpha level.

\section{FINDINGS}

Research Question 1: What is the achievement motivation level of undergraduates in Nigeria?

In order to answer this research question, participants' responses on the achievement motivation scale were collated and categorised into two levels; high and low. The summary of the results is as shown on table 1 .

Table 1

Level of achievement motivation of undergraduates in Nigeria

\begin{tabular}{lll}
\hline Level of Achievement Motivation & Frequency & Percentage $(\%)$ \\
\hline High & 1103 & 71.81 \\
Low & 433 & 28.19 \\
Total & 1536 & 100 \\
\hline
\end{tabular}

Table 1 indicates that 1,536 undergraduates participated in this study. Responses to items that sought information on achievement motivation of undergraduates revealed that 1103 representing $(71.81 \%)$ of the respondents had high level of achievement motivation, while 433 representing $(28.19 \%)$ of the respondents had low level of achievement motivation. This indicates that the level of achievement motivation of undergraduates in Nigeria was high.

\section{Research Question 2: $\quad$ What is the attitude of undergraduates in Nigeria} towards examination?

In order to answer this research question, participants' responses on the attitude of undergraduates in Nigeria towards examination scale were collated and categorised into two levels; high and low. The summary of the results is as shown on table 2.

Table 2

Attitude of undergraduates in Nigeria towards examination

\begin{tabular}{lll}
\hline Attitude of Undergraduates Towards Examination & Frequency & Percentage (\%) \\
\hline Positive & 1118 & 72.79 \\
Negative & 418 & 27.21 \\
Total & 1536 & 100 \\
\hline
\end{tabular}

Table 2 indicates that 1,536 undergraduates participated in this study. Responses to items that sought information on attitude of undergraduates in Nigeria towards examination revealed that 1118 representing $(72.79 \%)$ of the participants had positive attitude towards examination, while 418 representing $(27.21 \%)$ of the participants had negative attitude towards examination. This indicates that the attitude of undergraduates in Nigeria was positive towards examination. 
Hypothesis One:

There is no significant correlation between
achievement motivation and attitude of
undergraduates towards examination in Nigeria

In order to test this hypothesis, participants' responses to the scales (Achievement Motivation and Attitude of Undergraduates Towards Examination) were collated. The data collected from the study were analysed using Pearson Product Moment Correlation statistics. Summary of the analysis is presented on Table 3.

Table 3

Correlation between achievement motivation and attitude of undergraduates towards examination in Nigeria

\begin{tabular}{lcccccc}
\hline Variables & $\mathrm{N}$ & Mean & SD & df & Cal. r-value & p-value \\
\hline Achievement Motivation & 1536 & 63.30 & 6.04 & 1534 & $0.55^{*}$ & 0.001 \\
Attitude Towards Examination & 1536 & 66.82 & 6.33 & & & \\
\hline
\end{tabular}

*Significant, $\mathrm{p}<0.05$

The result on Table 3 indicates that the calculated $r$ is 0.55 and the p-value is 0.001 . Since the calculated $\mathrm{p}$-value is less than the alpha level at 0.05 , indicating a significant relationship. Hence, the hypothesis which states that there is no significant correlation between achievement motivation and attitude of undergraduates towards examination in Nigeria was rejected. This means that there was a significant positive correlation between achievement motivation and attitude of undergraduates towards examination in Nigeria.

Hypothesis Two: Gender, age, level of study, university and family type will not influence undergraduates' achievement motivation and attitude towards examination in Nigeria

In order to test this hypothesis, participants' responses to the scales (Achievement Motivation and Attitude of Undergraduates Towards Examination) were collated. The data collected from the study were analysed using multiple regression statistics. Summaries of the analysis are presented on Tables 4 and 5.

Table 4

Analysis of variance (ANOVA) showing the regression between the predictors variables and the dependent variable

\begin{tabular}{llclcc}
\hline Model & Sum of Squares & df & Mean Squares & Cal. F-ratio & p-value \\
\hline Regression & 15590.129 & 5 & 3118.0258 & $28.57 *$ & $.000^{\mathrm{b}}$ \\
Residual & 166952.974 & 1530 & 109.120 & & \\
Total & 182543.103 & 1535 & & & \\
\hline
\end{tabular}

*Significant, $\mathrm{p}<0.05$

a. Dependent Variable: ATE

b. Predictors: (Constant), AM, Family Type, University, Age, Gender, Level

of study 
Table 5

Regression coefficient showing gender, age, level of study, university and family type correlating with undergraduates' achievement motivation and attitude towards examination

\begin{tabular}{llllll}
\hline Model & B & Std. Error & Beta & Cal t-value & p-value \\
\hline Constant & 132.483 & 1.868 & & 68.842 & .000 \\
Gender & 1.113 & .570 & .051 & $1.954^{*}$ & .051 \\
Age & 1.599 & .564 & .075 & $2.838^{*}$ & .005 \\
Level of Study & 2.799 & .333 & .228 & $8.406^{*}$ & .000 \\
University & .118 & .156 & .019 & .758 & .448 \\
Family Type & 1.590 & .624 & .068 & $2.547^{*}$ & .011 \\
\hline
\end{tabular}

Table 4 shows the result of the ANOVA table indicating an F-value of $F(5,1530)=28.57$, $\mathrm{p}<0.05$. This implies that the correlation between the predictors and outcome variables are statistically significant. Table 5 further expressed the result of the relative contribution of moderating variables (gender, age, level of study, university and family type) correlating with undergraduates' achievement motivation and attitude towards examination. Gender have a Beta weight $(\beta)$ of $1.113, \mathrm{t}=1.954, \mathrm{p}<0.05$; age have a Beta weight $(\beta)$ of $1.599, \mathrm{t}=$ 2.838, $\mathrm{p}<0.05$. Level of Study have a Beta weight $(\beta)$ of $2.799, \mathrm{t}=8.406, \mathrm{p}<0.00$; university type have a Beta weight $(\beta)$ of $.118, \mathrm{t}=.758$; while family type have a Beta weight (â) of $1.590, t=2.547, \mathrm{p}<0.05$. Gender, age, level of study and family type has a relationship with undergraduates' achievement motivation and attitude towards examination in Nigeria. Therefore, hypothesis two which states that gender, age, level of study, university and family type will not influence undergraduates' achievement motivation and attitude towards examination in Nigeria was hereby rejected.

\section{Summary of the Findings}

Based on the data collected, analysed and interpreted, the following findings were obtained:

i. the achievement motivation level $(71.81 \%)$ of the undergraduates sampled for this study was high based on their response to the achievement motivation scale used for the study;

ii. the attitude towards examination $(72.79 \%)$ of sampled undergraduates was positive, based on their responses to the attitude towards examination scale used for the study;

iii. there was a significant positive correlation between achievement motivation and attitude of undergraduates towards examination (calculated p-value of $0.003<$ alpha level of 0.05); and

iv. gender, age, level of study, university and family type had a significant positive influence on undergraduates' achievement motivation and attitude towards examination $(\mathrm{F}$-value of $\mathrm{F}(5,1530)=28.57$, $\mathrm{p}<0.05)$.

\section{DISCUSSION}

The findings of this study revealed that undergraduates in Nigeria had a high level of achievement motivation. Some of the items which majority of the respondents chose as a result of having a high achievement motivation include: always wanting to learn as much 
as possible from the lessons in their class; setting goal in the classroom which includes: to avoid performing poorly; and avoiding performing poorly in the class among others. This finding agrees with the findings of Sadiq (2014) who found that motivation of Nigeria Army School of Education students was high. Also, Eric and Barnie (2014) found that the achievement motivation of high school students in Ghana was high. Aremu and Oluwole (2001); Adeyemo and Oluwole (2001) and Odedele (2000) have submitted that the way and manner the child perceived himself could affect his academic performance. This may be due to the development of study skills. In a society which places emphasis on academic work proper, inculcation of good study habits and learning skills increases academic performance in schools.

Another finding of this study revealed that undergraduates in Nigeria displayed a positive attitude towards examination. Some of the items which majority of the respondents chose as a result of having a positive attitude towards examination include: reading instructions before starting examinations; going to examination hall with the required examination materials; reviewing answers before submission of examination scripts among others. This finding is in consonance with that of Colin and Barbara (2013) who found that students of University of Rzeszow have positive attitude towards examination. This present finding negates the findings of Adegboyega (2016) who examined the relationship between emotional intelligence and attitude towards examination of undergraduates at University of Ilorin and found that majority of the respondents have negative attitude towards examination, because only $32 \%$ had positive attitude and $68 \%$ had negative attitude. In a meta-analysis, Crede and Kuncel (2008) found that non-cognitive factors like study habits, skill and study motivation, among other attitudinal constructs, accounted for incremental variance in academic performance beyond standardized tests and previous grades. Moreover, a literature review by Nagaraju (2004) pointed out that, for a good academic success, good study habits and attitudes are important. The positive attitude displayed by undergraduates in Nigeria towards examination might have been reinforced by stake holders in education sector to control or minimise students' poor academic performance. The positive attitude displayed by undergraduates in Nigeria towards examination could also be presumed to have resulted from lecturers' improvement in their roles as learning facilitators which have helped the students to display a positive attitude towards examination.

Hypothesis one revealed that there was a significant positive correlation between achievement motivation and attitude of undergraduates towards examination in Nigeria. The implication of this is that appropriate achievement motivation will lead to positive attitude to examinations and vice-versa. This finding is in consonance with National Centre for Clinical Infant Programs (2013) who stated that a student who seeks to learn is much more apt to succeed. On the contrary, Cornelius and Nsisong (2014) found that academic achievement motivation and attitude of senior secondary school students towards examination malpractice in Uyo Metropolis, Akwa Ibom State, Nigeria.

Hypothesis two revealed that gender, age, level of study, university and family type had a significant positive influence on undergraduates' achievement motivation and attitude towards examination in Nigeria. This implies that the correlation between the predictors 
and outcome variables are statistically significant. This finding is in consonance with that of Cox (2010) and Michelli (2013) who found that gender was proven to affect attitudes, it did not affect achievement significantly as both genders scored approximately the same on the math test portion of the questionnaire. These findings conflict with other studies that claim students, particularly females, with negative attitudes score poorly. This difference could be attributed to the particular type of negative attitudes these students felt.

The finding agrees with the findings of Nuthana and Yenagi (2009) who stated that the achievements of students in courses are usually determined by their scores in given examinations. Achievement motivation ensures that a student uses all his/her time and energy to achieve the standard objectives set before him/her. Nuthana and Yenagi also stated that achievement motivation of students plays a role in the attitude students have toward their schooling and their academic success. Goc (2010) further outlined some factors that affect students' achievement motivation and in turn affect their attitude toward their studies and examination including effectiveness of the teacher, friends, the individual's attitude towards school, students' perceptions about their own abilities, past experiences (positive or negative), the importance given to the student's success, parent's approaches towards their children and school by taking into account the researches done.

\section{CONCLUSION}

Based on the findings of the study, the following conclusions were drawn:

Majority of Nigerian undergraduates have a high level of achievement motivation. The findings also revealed that majority of Nigerian undergraduates have a positive attitude towards examination. There was a significant correlation between achievement motivation and attitude of Nigerian undergraduates towards examination. Students with high achievement motivation tend to have a positive attitude towards examination. The findings also revealed that gender, age, level of study, university and family type had a significant positive influence on undergraduates' achievement motivation and attitude towards examination in Nigeria.

\section{RECOMMENDATIONS}

Based on the findings of this study, the following recommendations were made:

Students should continue to develop a positive attitude towards examination. This is because for an individual to be promoted, he/she needs to be assessed on what was taught. Therefore, when students become more focused on their studies, treasure and value education, they would know the reason why they are in school and would thus not cut-corners to pass examinations. Examinations would thus be seen as a test to assess an individual's mastery of the concept taught.

Professional counsellors should endeavour to use appropriate therapies in their institutions of learning by organizing seminars that will help them to understand the influence of achievement motivation on undergraduates' attitude towards examination within the tertiary institutions. These undergraduates can also be helped to identify their true position and attitude towards examinations as well as the need to set valuable 
targets for high academic attainment and they should thus be encouraged from time to time on the need to seek counselling in the area of goal setting for high academic achievement.

\section{REFERENCES}

Adegboyega, L. O. (2016). Relationship between emotional intelligence and attitude towards examination of undergraduates at University of Ilorin. Unpublished seminar paper, Department of Counsellor Education, University of Ilorin, Ilorin, Nigeria.

Adeyemo, D. A., \& Oluwole, D. A. (2001). Parental rejection extraversion, neuroticism and study habit as correlates of test anxiety among secondary school students in Oyo State, Nigeria. African Journal of Educational Planning and Policy Studies, 2(2), 15-23.

Annual Reports of Universities in Nigeria (2016). Population of undergraduate students in Nigeria.

Aremu, S., \& Oluwole, D. A. (2001). Gender and birth order as predictors of normal pupils anxiety patterns in examination. Ibadan Journal of Educational Studies, 1(1), 175-181.

Brophy, J. (1998). Motivating students to learn. Madison, WI: McGraw Hill.

Cladella, K., \& Herlin, C. (2002). ERIC Information Center Resources [ED473816].

Colin, F. H., \& Barbara, F. (2013). An examination of students' attitudes and preparedness for the introduction of ICT-enabled learning at university. Computer Science and Information Systems, 1, 99-104.

Cornelius, C. O., \& Nsisong, A. U. (2014). Academic achievement motivation and attitude of senior secondary school students towards examination malpractice in Uyo metropolis, Akwa-Ibom State, Nigeria. IOSR Journal of Research \& Method in Education, 4(5), 25- 31.

Cox, L. (2010). Girls good at math, but teachers may make them anxious about it. Retrieved July 2012, from ABC News:www.abcnews.go.com/Health/MindMoodNews/teachers-mathanxiety-convincesgirls-bad-math-study/story?id=9658944\#.UHxu-bRzOfQ

Crede, M., \& Kuncel, N. (2008). Study habits meta-analysis. Perspectives on Psychological Science, 3(6), 425-453.

Dörnyei, Z. (2001). Teaching and researching motivation. Harlow: Pearson Education Limited.

Dowson, M. \& McInerney, D. M. (2001). Psychological parameters of students' social and work avoidance goals: A qualitative investigation. Journal of Educational Psychology, 93(1), 35-42.

Drago, J. M. (2004). The relationship between emotional intelligence and academic achievement in non-traditional college students. Doctoral Dissertation, Walden University.

Elliot, A. J., \& Mcgregor, H. A. (2001). A 2x2 achievement goal framework. Journal of Personality and social psychology, 80, 501-519.

Eric, A. A., \& Barnie, J. (2014). Achievement motivation, academic self-concept and academic achievement among high school students. European Journal of Research and Reflection in Educational Sciences, 2(2), 24-37.

Fidan, N. (1993). Okulda ögrenme ve öğretme, [Learning and teaching in classroom 
setting]. Ankara: Alkım Yayınevi.

Gesinde, A. M. (2000). Motivation. In Z.A.A. Omideyi (Ed.). Fundamental of guidance and counselling (pp. 12-26). Ibadan: Kanead Publishers.

Goc, T. (2010). M. A. Thesis, Dokuz Eylul University, Izmir, Turkey.

Kaplan, A., \& Maehr, M. L. (2007). The contributions and prospects of goal orientation theory. Educational Psychology Review, 19, 141-184.

Michelli, M. P. (2013). The relationship between attitudes and achievement in mathematics among fifth grade students. Honors Theses. Paper 126.

Nagaraju, M. T. (2004). Study habits of secondary school students. New Delhi: Discovery Publishing House.

National Centre for Clinical Infant Programs (2013). Zero to three gains a new initiative, Project LAUNCH (Linking Actions for Unmet Needs in Children's Health); Project LAUNCH is a state, tribal and community-based focal point for early childhood systems development funded by the Substance Abuse and Mental Health Services Administration (SAMHSA).

Nouhi, E., Shakoori, A., \& Nakhei, N. (2008). Study habits and skills, and academic achievement of students in Kerman University of medical sciences. Journal of Medicine Education, 12(3\&4), 77-80.

Nuthana, P. \& Yenagi, G. (2009). Influence of study habits, self-concept on academic achievement of boys and girls. Kartanaka Journal of Agricultural Science, 22(5), 11351138.

Nuthanap, G. (2007). Gender analysis of academic achievement among high school students. Unpublished thesis submitted to the Department of Human Development, College of Rural Home Science, Dharwad University of Agricultural Sciences.

Odedele, A. R. (2000). Test anxiety and self-efficacy as correlates of academic performance among secondary school students. Unpublished M.Ed. Dissertation, University of Ibadan, Ibadan.

Okoye, N. N. (1985). The psychology of motivation. Ibadan: Adebara Publishers Limited, Ibadan, Nigeria.

Paul, S. (1982). Achievement motivation. In H. E. Mitzel (Ed.) Encyclopedia of Educational Research, Volume 4, New York: The Free Press.

Research Advisors (2006). Sample size table: Required sample size. http://www.researchadvisors.com/tools/samplesize.

Sadiq, A. (2014). Relationship among students self concept, motivation and academic achievement in Nigeria army school of education, Ilorin, Kwara State. Unpublished M.Ed. project, University of Ilorin, Ilorin, Nigeria.

Stangor, C. O. (2004). Research methods for behavioural sciences. Boston: Houghton Mifflin Co.

Tucker, C. M., Zayco, R. A., \& Herman, K. C. (2002). Teacher and child variables as predictors of academic engagement among low-income African American children. Psychology in the Schools, 39(4), 477-488. 